\title{
Adaptação do Indicador de Salubridade Ambiental - ISA para análise de empreendimentos do Programa de Arrendamento Residencial - PAR em Aracaju/SE
}

\section{Indicator of Environmental Health- IEH Adaptation for Analysis of the Social Housing Program - SHP in Aracaju/SE}

\author{
Cristina Fernandes de Oliveira Buckley* \\ Engenheira Civil, Mestre em Desenvolvimento e Meio Ambiente, Rede PRODEMA, \\ Universidade Federal de Sergipe (UFS). E-mail: cristinabuckley@hotmail.com
}

\section{José Daltro Filho}

Engenheiro Civil, Doutor em Hidráulica e Saneamento, Escola de Engenharia de São Carlos/USP. Professor Adjunto do Departamento de Engenharia Civil da Universidade Federal de Sergipe (UFS). Orientador do Mestrado em Desenvolvimento e Meio Ambiente, Rede PRODEMA, Universidade Federal de Sergipe (UFS). E-mail: jdaltro@ufs.br

*Endereço para correspondência: SAFS Quadra 4, Lote 1, Anexo I, Sala 104 - Brasília - DF - CEP 70042-900

e-mail: cristinabuckley@hotmail.com

Data de Entrada: 13/01/2010

Data de aprovação: 01/12/2011

\section{RESUMO}

O desenvolvimento sustentável deve promover a qualidade de vida da população, incluindo a saúde e o saneamento da habitaçáo. Um instrumento para avaliar os efeitos sobre a salubridade do ambiente é o Indicador de Salubridade Ambiental - ISA, utilizado por diversos autores com adaptaçóes, conforme a especificidade do objeto de estudo. Diante da grande aceitação do Programa de Arrendamento Residencial PAR em Aracaju/SE e a localização de grande parte dos empreendimentos em áreas de preservaçáo permanente, foi utilizado o indicador ISA/PAR para avaliar os impactos causados sobre beneficiários e entorno. Este indicador baseia-se em oito sub-indicadores, e os seis empreendimentos analisados evidenciaram boas condiçôes, exceto esgotamento sanitário, controle de vetores e espaço público em alguns deles.

Palavras-chave: Desenvolvimento sustentável; saneamento ambiental; arrendamento residencial.

\section{ABSTRACT}

Sustainable development must provide life quality to the population, including health and house sanitation. One of the means for evaluating the effects over the health of the environment is the Indicator of Environmental Health- IEH, used by several authors after being adapted to its specific subject. Considering the Social Housing Program - SHP great acceptation in Aracaju/SE and the location of most condos in areas of environmental protection, the indicator IEH/SHP is used in this research to evaluate the impacts over the beneficiaries and their neighborhood. This indicator is based upon the sub-indicators Water Supply, Sanitation, Solid Wastes, Vector Control, Public Places, Housing Conditions, Housing Satisfaction and Impacts over the Neighborhood. The six condos analyzed showed good conditions, except sanitation, vector control and public places in some of them.

Keywords: Sustainable development; environmental sanitation; social housing.

\section{INTRODUÇÂO}

Qualidade de vida é um conceito (LEFF, 2001) que vem ganhando notoriedade, tendo em vista que o crescimento das cidades muitas vezes tem causado seu prejuízo. Especialmente em áreas habitadas por populaçóes de baixa renda, o crescimento populacional tem trazido problemas a moradores e administradores, 
traduzidos justamente nesta perda de qualidade. Um destes grandes problemas é a questão da saúde pública e do saneamento ambiental (DALTRO FILHO, 2004). Saúde é um conceito que não está adstrito meramente ao individual, uma vez que o homem é um ser que vive em coletividades e, portanto, a saúde de um indivíduo ou sua ausência pode trazer importantes reflexos sobre toda a populaçáo. Deste modo, o saneamento justificase como preocupação do Poder Público.

Entretanto, outras políticas públicas devem necessariamente ser levadas em conta quando o que se busca é a qualidade de vida da população. As políticas habitacionais atingem diretamente suas condiçóes de vida presentes e futuras, da mesma forma que as políticas ambientais, limitadoras da ocupaçáo territorial. Portanto, náo basta fornecer moradia à populaçáo. As habitaçốes, notadamente as situadas nas cidades, necessitam atender a diferentes requisitos mínimos de salubridade, bem como ser beneficiadas com açóes de saneamento urbano e proteçáo ao meio ambiente proporcionadas pelo Poder Público, de modo a garantir o oferecimento de condiçốes de vida aceitáveis.

Para possibilitar uma melhor compreensão do quadro de problemas e soluçôes que hoje surgem, uma análise histórica das sociedades humanas revela que, ao longo do tempo, diferentes visóes do que seria desenvolvimento estấo intimamente atreladas a diferentes visôes da natureza e, por sua vez, ligadas às formas de ocupação territorial e de moradia. O modelo de desenvolvimento capitalista trouxe problemas ambientais e sociais com graves consequências para o bem-estar e saúde da própria humanidade, como poluiçáo do ar e da água, erosáo de solos, desertificação, problemas de abastecimento de água; danos à camada de ozônio, aquecimento global, distúrbios climáticos etc. $\mathrm{O}$ ar das cidades tornou-se irrespirável justamente em consequência das indústrias que simbolizavam a civilizaçáo (DIEGUES, 1996), e o processo de urbanização, mantido "às custas da degradação das condiçóes de sustentabilidade global do planeta" (LEFF, 2001, p. 292), tornou os espaços de habitabilidade saturados. Deste modo, o modelo capitalista de desenvolvimento passou a ser duramente questionado, ante o comprometimento da satisfaçáo das necessidades humanas básicas, levando à busca do chamado desenvolvimento sustentável, que incorpora soluçōes que levam em conta as dimensóes sociais, políticas e culturais, com o fim último de promover a melhoria da qualidade de vida (CAMARGO, 2003). Nesta nova concepção, conforme explanam Gomes et al. (1995), o desenvolvimento náo se apóia unicamente no crescimento, mas também na ampla difusão de seus benefícios e na preservaçấo ambiental.

Dentre as tentativas de interferir positivamente na qualidade de vida da populaçáo, destaca-se o Saneamento Ambiental, concebido como uma série de medidas e açôes que têm por objetivo oferecer não apenas água potável e tratamento de efluentes, mas um conjunto de condiçốes em níveis crescentes de salubridade (CARVALHO, 1980). Para aferir estes níveis, vários indicadores sócio-ambientais têm sido propostos, sendo um deles o Indicador de Salubridade Ambiental - ISA, definido pelo Conselho Estadual de Saneamento do Estado de São Paulo - CONESAN para avaliar a eficácia de seu Plano Estadual de Saneamento (ALMEIDA e ABIKO, 2000). Seu cálculo permite aferir o quanto uma área oferece boas condições de vida, dentro do que preconiza o Saneamento Ambiental. Este indicador vem sendo utilizado com adaptaçôes por diversos estudiosos, conforme sua área de interesse específica: Dias et al. (2004) criaram o ISA/OE (aplicado a áreas de ocupação espontânea de Salvador/BA); Batista e Silva (2008) criaram o ISA/JP (aplicado a bairros costeiros de João Pessoa/PB); Silva (2006) propôs nova adaptação, denominada ISA/JP1 (aplicado a comunidades periurbanas na bacia do bairro Gramame/PB); Almeida e Abiko (2000) criaram o ISA/F (aplicado a favelas em áreas de proteçấo a mananciais em São Paulo/SP).

$\mathrm{Na}$ esteira do oferecimento de qualidade de vida à população, o Governo Federal, visando à ampliação de investimentos públicos e privados no país até 2010, lançou recentemente o Programa de Aceleração do Crescimento - PAC, adotando medidas que incluem estímulo ao crédito e expansão da infra-estrutura, compreendendo obras em diversas áreas, entre as quais saneamento e habitação (BRASIL, 2007). Assim, previuse o fortalecimento do Programa de Arrendamento Residencial - PAR, criado pela Lei no 10.188 , de 12 de fevereiro de 2001, para atendimento às necessidades de moradia da populaçáo de baixa renda, ou seja, com renda familiar até seis salários mínimos (CAIXA, 2008).

Uma das cidades brasileiras nas quais o PAR teve maior aceitação é Aracaju/SE, que totalizava, em março de 2008, 37 empreendimentos entregues à populaçáo. Outro fato que merece destaque refere-se ao histórico de ocupaçấo territorial da cidade, caracterizado pela destruição de manguezais e dunas para instalação de empreendimentos imobiliários (CORREA e ANJOS, 2007), e que se perpetua até aos dias de hoje, inclusive para abrigar conjuntos habitacionais, notadamente os 
do PAR. Alguns destes empreendimentos sáo localizados próximos a áreas de preservação, o que potencializa seus impactos ambientais.

A análise destes empreendimentos em Aracajué, portanto, o foco deste estudo, verificando o efetivo atendimento às condiçóes objetivas para que as unidades sejam consideradas salubres e adequadas ao oferecimento de melhor qualidade de vida a seus beneficiários, bem como aos ocupantes do entorno. Apesar da adequaçáo do ISA como forma de mensurar as condiçóes de salubridade de um ambiente genérico (que pode ou náo ter sido objeto de urbanização), as especificidades do PAR (como, por exemplo, exigência de sistemas de abastecimento e coleta de resíduos sólidos como condicionante para aprovação dos projetos) recomendam a adaptaçáo do ISA para análise de empreendimentos do PAR, gerando o indicador ISA/PAR proposto neste trabalho.

\section{METODOLOGIA}

O indicador ISA/PAR é composto pelos seguintes subindicadores:

- Abastecimento de Água $\left(\mathrm{I}_{\mathrm{AB}}\right)$ : baseado nas variáveis Qualidade da Água (QA), Frequência do Abastecimento (FA) e Reservação (RE), segundo a Equaçăo 1:

$I_{A B}=0,40 Q A+0,30 F A+0,30 R E$

- Esgotamento Sanitário $\left(\mathrm{I}_{\mathrm{ES}}\right)$ : baseado nas variáveis Destino dos Dejetos Sanitários (DS) e Destino das Águas Servidas (AS), segundo a Equaçăo 2:

$I_{E S}=0,50 D S+0,50 A S$

- Resíduos Sólidos $\left(\mathrm{I}_{\mathrm{RS}}\right)$ : baseado nas variáveis Acondicionamento Doméstico (AD), Deposiçẫo Condominial (DC) e Regularidade de Coleta (RC), segundo a Equação 3:

$I_{R S}=0,35 A D+0,35 \mathrm{DC}+0,30 R C$

- Controle de Vetores $\left(\mathrm{I}_{\mathrm{CV}}\right)$ : baseado nas variáveis para Dengue (VE), para Disenteria (VI), para Leptospirose (VL), para Toxoplasmose (VT) e Incidência de doenças (ID), segundo a Equação 4:
$I_{C V}=0,20 \mathrm{VE}+0,20 \mathrm{VI}+0,20 \mathrm{VL}+0,20 \mathrm{VT}+0,20$

ID

- Espaço Público ( $\left.\mathrm{I}_{\mathrm{EP}}\right)$ : baseado nas variáveis Circulação (CI), Manutenção (MA), Pavimentação (PA), Alagamento (AL), Iluminaçáo Pública (IP), Lazer (LA), Equipamentos Urbanos (EU), Serviços (SV) e Segurança (SG), segundo a Equação 5:

$\mathrm{I}_{\mathrm{EP}}=0,12 \mathrm{CI}+0,10 \mathrm{MA}+0,10 \mathrm{PA}+0,12 \mathrm{AL}+0,12$

$\mathrm{IP}+0,12 \mathrm{LA}+0,08 \mathrm{EU}+0,12 \mathrm{SV}+0,12 \mathrm{SG}$ (5)

- Condiçôes de Moradia $\left(\mathrm{I}_{\mathrm{CM}}\right)$ : baseado nas variáveis Materiais (MT), Conforto Ambiental (CA), Instalaçōes Elétricas e Hidro-Sanitárias (EH) e Aglomeração (AG), segundo a Equaçáo 6:

$I_{C M}=0,25 \mathrm{MT}+0,25 \mathrm{CA}+0,25 \mathrm{EH}+0,25 \mathrm{AG}$

- Satisfaçáo com a Moradia $\left(\mathrm{I}_{\mathrm{SM}}\right)$ : baseado nas variáveis Percepção Individual (PI) e Desejo de Mudar-se (DM), segundo a Equação 7:

$I_{S M}=0,50 P I+0,50 D M$

- Impactos sobre o Entorno $\left(\mathrm{I}_{\mathrm{IE}}\right)$ : baseado na variável Percepçáo dos Ocupantes do Entorno (PE), em relação a todos os componentes anteriores.

Para o cálculo do ISA/PAR, foi empregada a Equação 8:

ISA/PAR $=0,15 I_{A B}+0,15 I_{E S}+0,10 I_{R S}+0,10 I_{C V}+0,10$ $\mathrm{I}_{\mathrm{EP}}+0,15 \mathrm{I}_{\mathrm{CM}}+0,10 \mathrm{I}_{\mathrm{SM}}+0,15 \mathrm{I}_{\mathrm{IE}}$

As faixas de salubridade utilizadas, às quais os resultados foram relacionados, consistem em situaçốes insalubres (de 0 a 0,300 pontos), de baixa salubridade (de 0,301 a 0,500 pontos), de média salubridade (de 0,501 a 0,800 ) e salubres (de 0,801 a 1 ponto).

A partir de um universo de 37 empreendimentos, foram escolhidos por amostragem probabilista sistemática seis deles: Residencial César Franco (Figura 1), Colina Residências (Figura 2), Residencial Bela Vista (Figura 3), Residencial Costa Norte (Figura 4), Residencial Horto do Carvalho I (Figura 5) e Residencial Sérgio Vieira de Melo (Figura 6), correspondentes a cerca de 15\% do total. 


\section{Artigos técnicos}

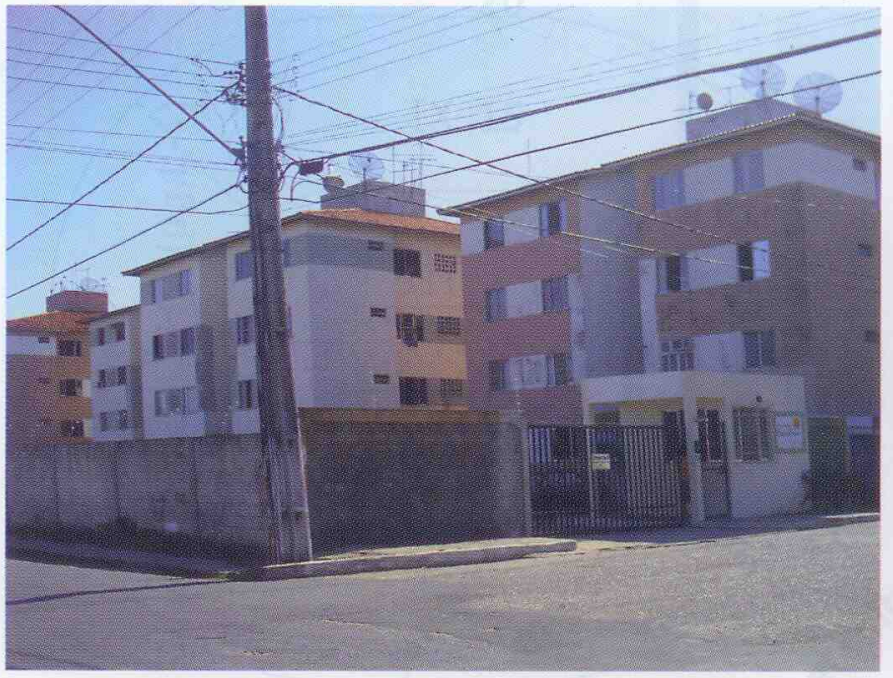

Figura 1 - Residencial César Franco

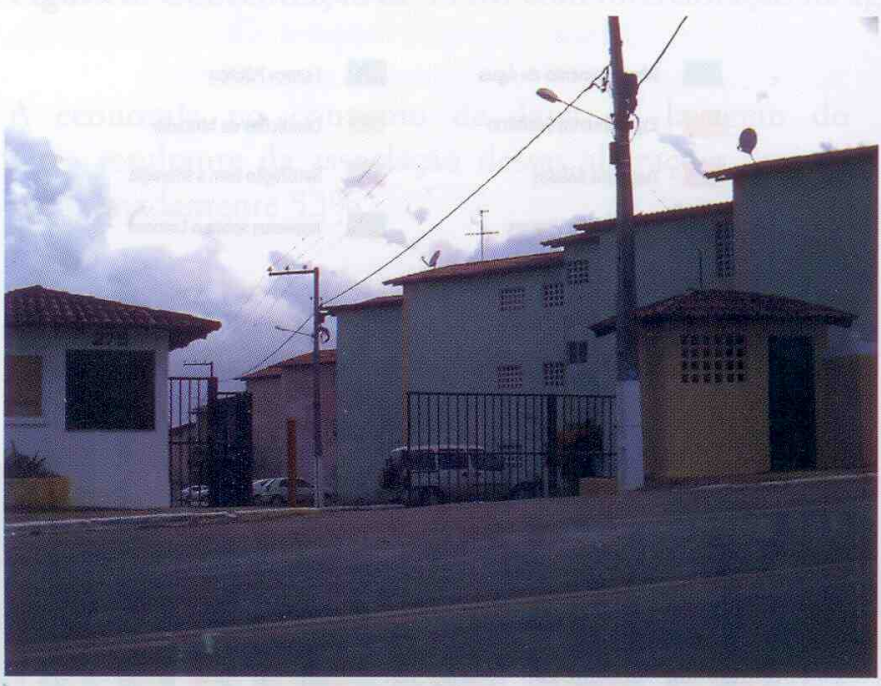

Figura 2 - Colina Residências

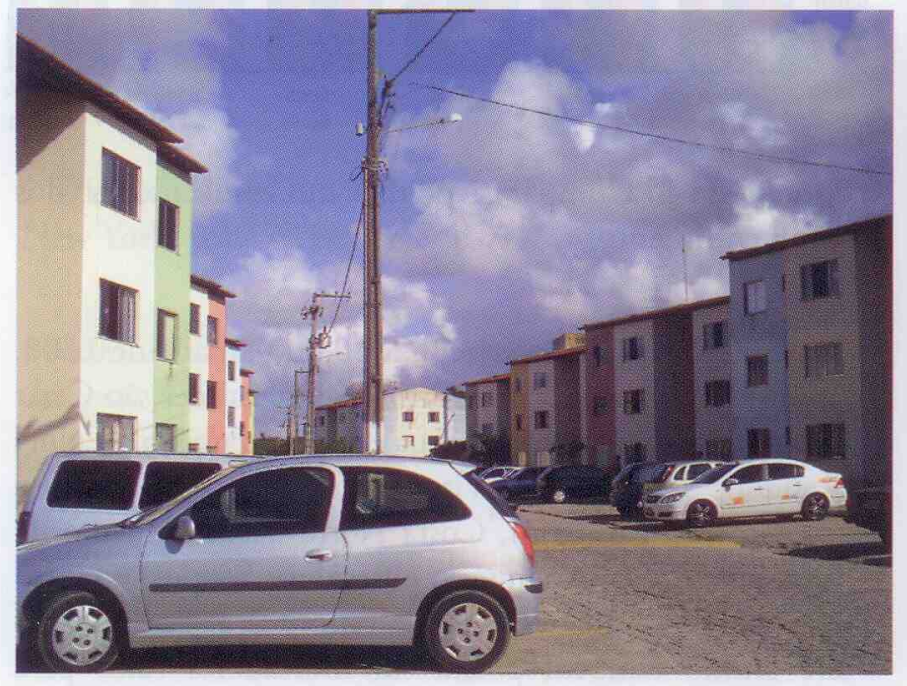

Figura 3 - Residencial Bela Vista

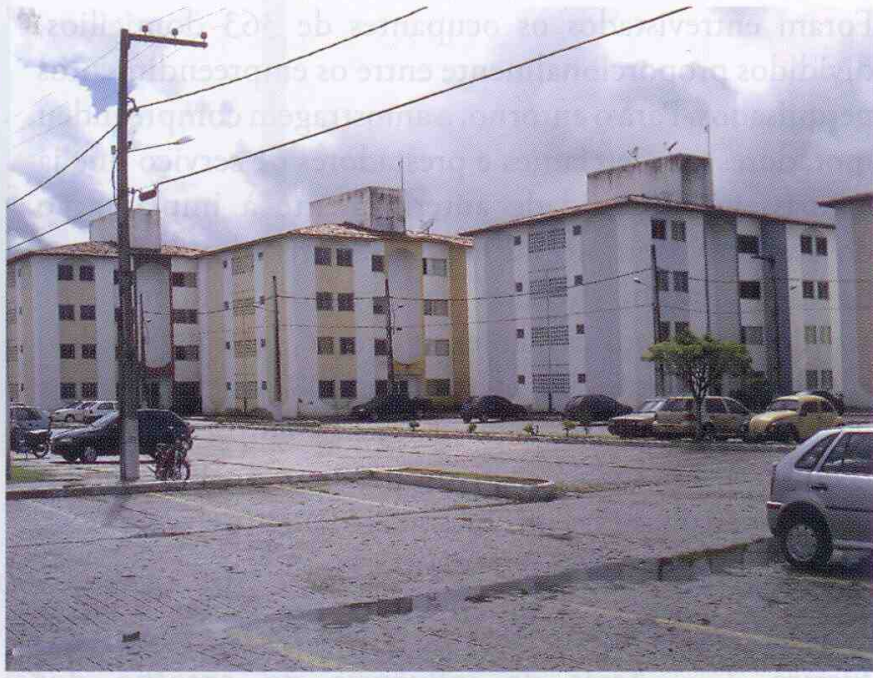

Figura 4 - Residencial Costa Norte

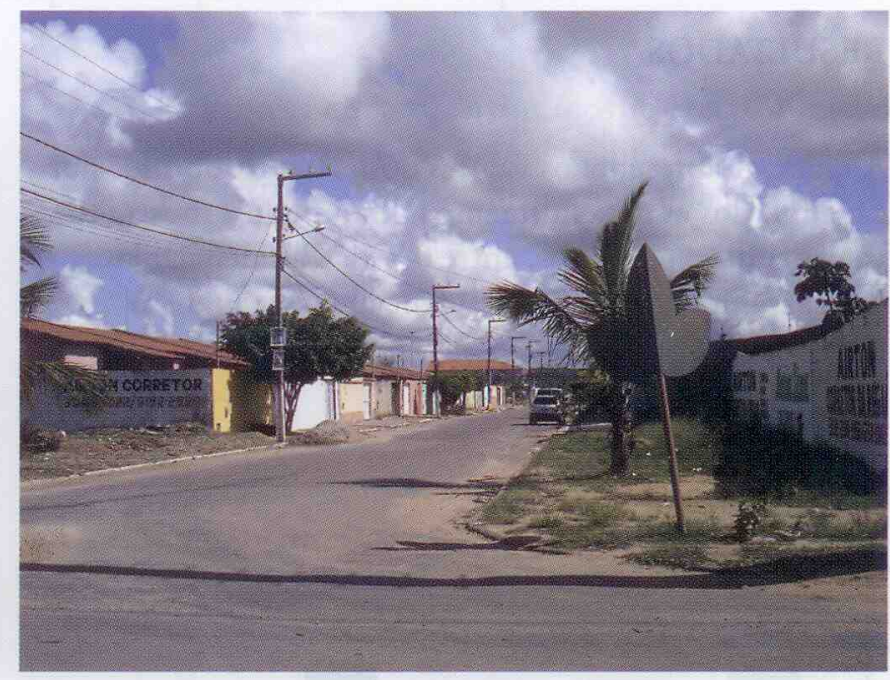

Figura 5 - Residencial Horto do Carvalho I

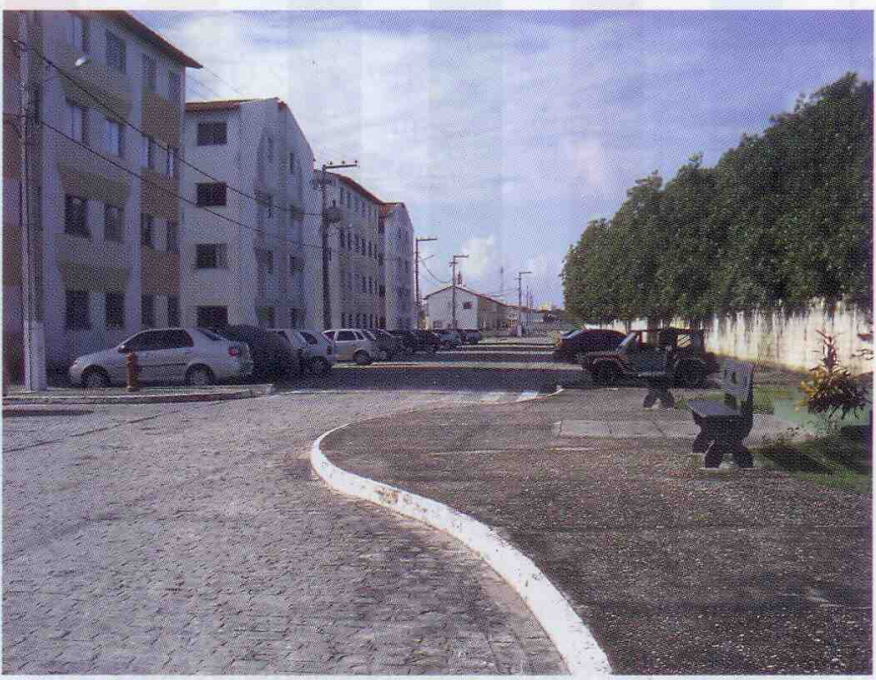

Figura 6 - Residencial Sérgio V. de Melo 
Foram entrevistados os ocupantes de 363 domicílios, divididos proporcionalmente entre os empreendimentos pesquisados. Para o entorno, a amostragem compreendeu moradores, comerciantes e prestadores de serviço que já ocupassem a localidade anteriormente à implantação do respectivo empreendimento. A área de vizinhança de cada um foi dividida em áreas de influência de acordo com o posicionamento (frente, laterais, fundos) e a distância (até 100 metros, de 100 a 200 metros e de 200 a 500 metros) em relaçáo ao empreendimento (Figura 7). Em cada área de influência, foi selecionado o máximo de duas casas e/ou estabelecimentos, tendo sido realizadas 55 entrevistas.

Figura 7 - Áreas de influência do entorno dos empreendimentos

\section{RESULTADOS}

A Figura 1 apresenta os valores do ISA/PAR obtidos por cada um dos empreendimentos pesquisados, mostrando valores muito próximos, entre 0,561 (Residencial Horto do Carvalho I) e 0,700 (Residencial César Franco).

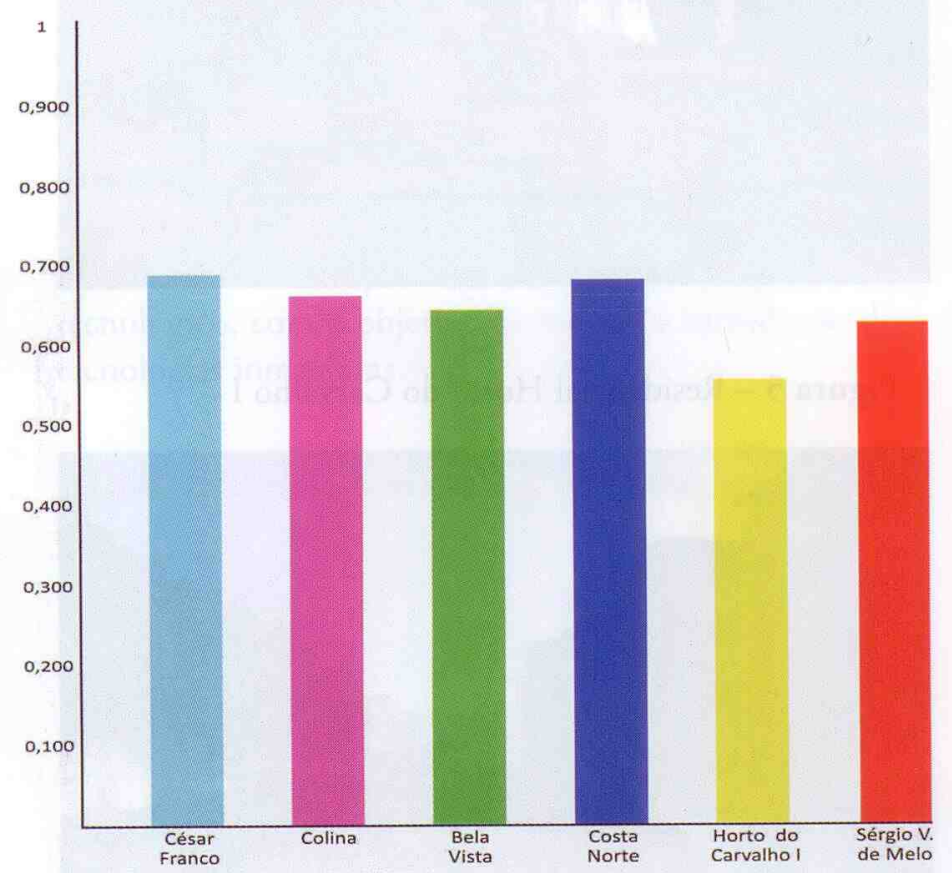

Figura 1 - Comparativo do ISA/PAR dos empreendimentos

A análise dos respectivos sub-indicadores permite uma visăo mais ampla da situaçáo de cada empreendimento, o que é feito na Figura 2.
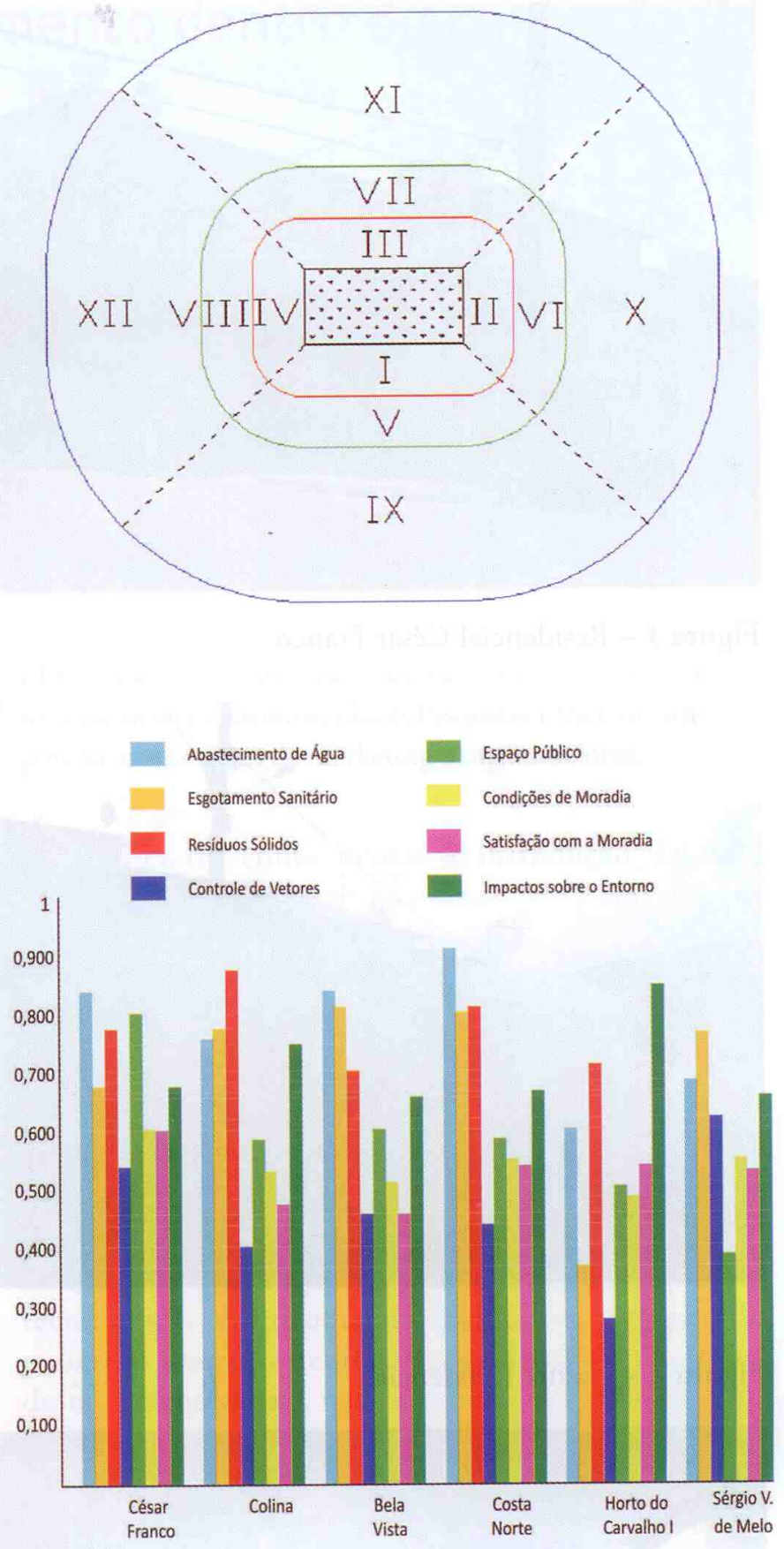

Figura 2 - Comparativo dos sub-indicadores dos empreendimentos

Destacando as pontuaçóes acima de 0,800 e abaixo de 0,300, os empreendimentos com bons sub-indicadores sáo César Franco (Abastecimento de Água e Espaço Público), Colina (Resíduos Sólidos), Bela Vista (Abastecimento de Água e Esgotamento Sanitário), Costa Norte (Abastecimento de Água, Esgotamento Sanitário e Resíduos Sólidos) e Horto do Carvalho I (Impactos sobre o Entorno). Por outro lado, este último também possui sub-indicadores ruins para Esgotamento Sanitário e Controle de Vetores. Sérgio Vieira de Melo apresentou sub-indicadores na faixa intermediária. 
Para uma análise mais aprofundada, as variáveis que os compóem permitem avaliar os pontos fracos e fortes de cada empreendimento, o que é feito nas Figuras 3 a 10.

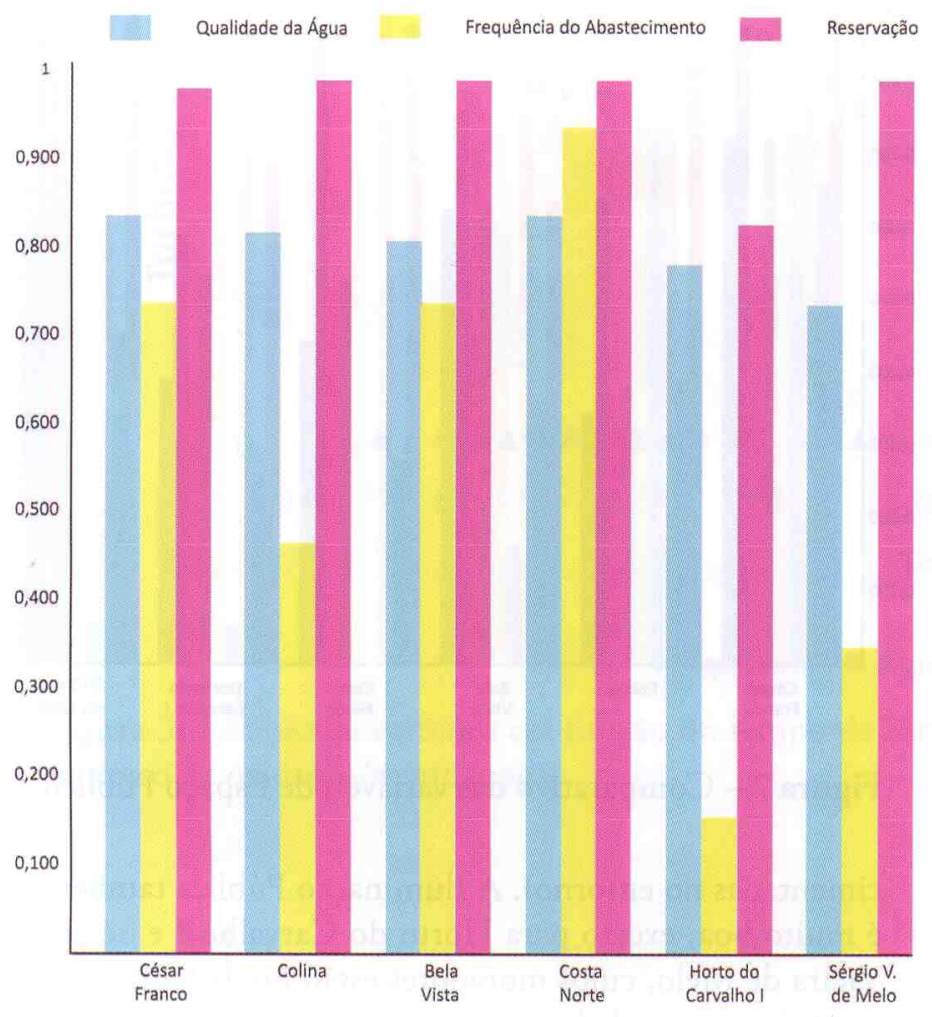

Figura 3 - Comparativo das variáveis de Abastecimento de Água

Apenas César Franco, Colina, Bela Vista e Costa Norte tiveram ótima pontuaçáo para Qualidade da Água, enquanto Horto do Carvalho I e Sérgio Vieira de Melo apresentaram pontuaçáo baixa. Todos apresentaram pontuação ótima para Reservaçáo. Quanto à Frequência do Abastecimento, Costa Norte se destacou positivamente e Horto do Carvalho I se destacou negativamente, evidenciando raríssima e excessiva falta d'água, respectivamente. Colina e Sérgio Vieira de Melo também apresentaram baixa pontuação, e os demais situaram-se na faixa intermediária.

Todos se situaram na faixa intermediária quanto ao Destino dos Dejetos Sanitários. Quanto ao Destino das Águas Servidas, entretanto, houve destaque positivo para Colina, Bela Vista, Costa Norte e Sérgio Vieira de Melo, enquanto Horto do Carvalho I se destacou negativamente (devido ao direcionamento do excedente para a sarjeta) e César Franco se situou na faixa intermediária.

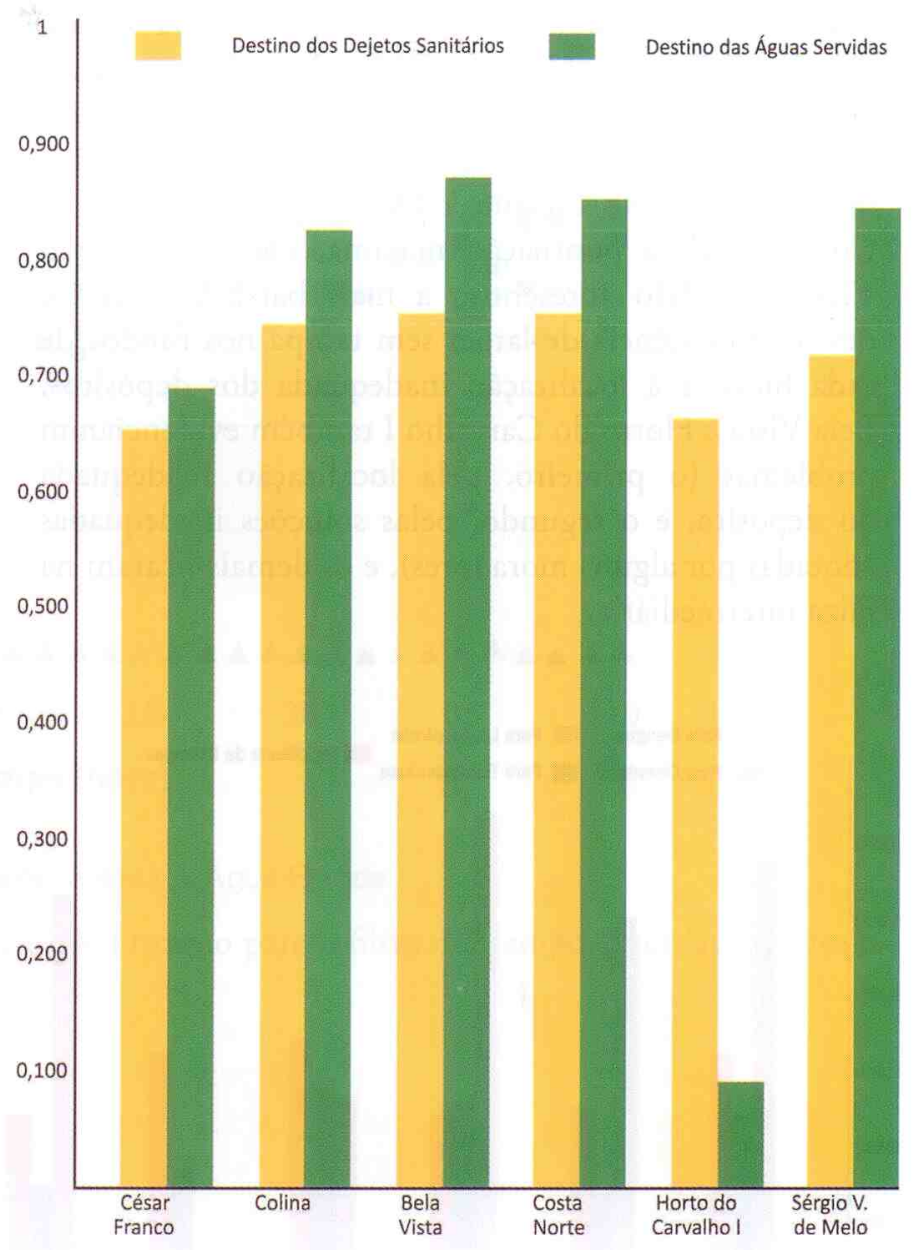

Figura 4 - Comparativo das variáveis de Esgotamento Sanitário

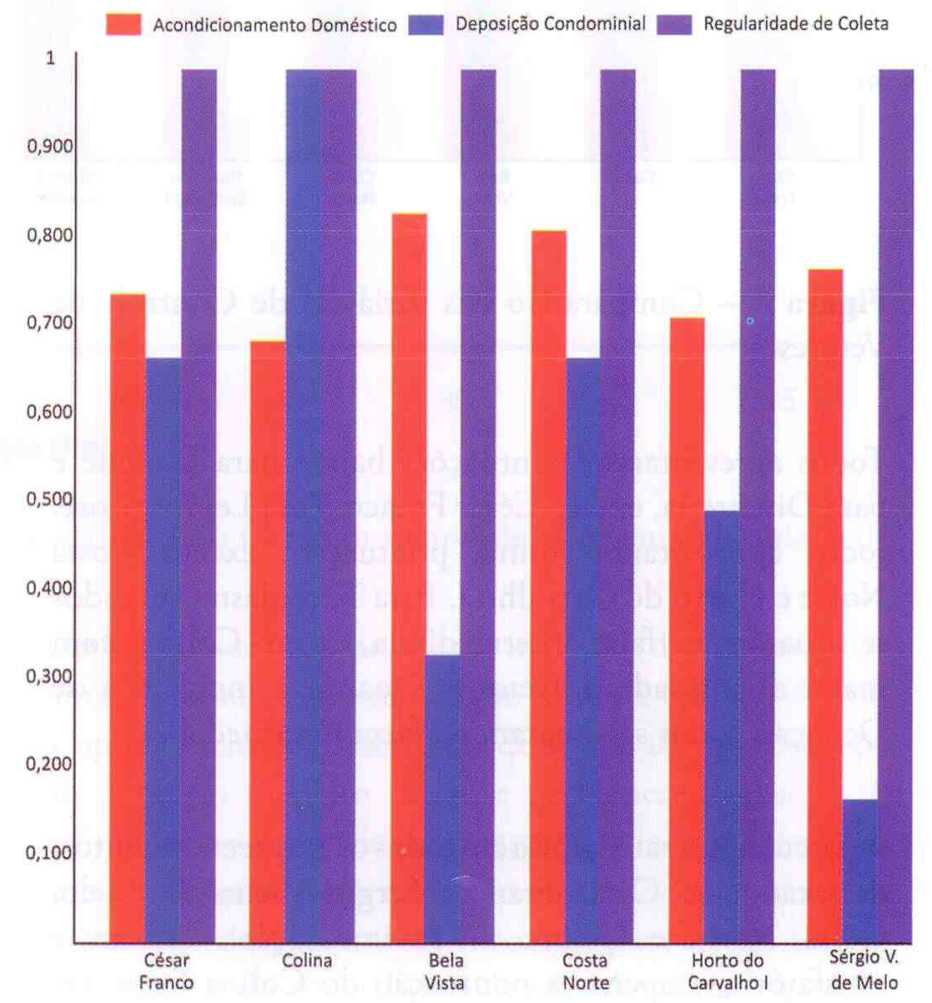

Figura 5 - Comparativo das variáveis de Resíduos Sólidos 
Todos apresentaram pontuação máxima para Regularidade de Coleta. Para Acondicionamento doméstico, apenas Bela Vista e Costa Norte tiveram ótimas pontuações, ficando os demais na faixa intermediária. No tocante à Deposiçãa Condominial, Colina recebeu pontuação máxima, enquanto Sérgio Vieira de Melo apresentou a mais baixa pontuação, devido à existência de latóes sem tampa nos fundos de cada bloco e à localização inadequada dos depósitos. Bela Vista e Horto do Carvalho I também evidenciaram problemas (o primeiro, pela localização inadequada do depósito, e o segundo, pelas soluçóes inadequadas adotadas por alguns moradores), e os demais ficaram na faixa intermediária.

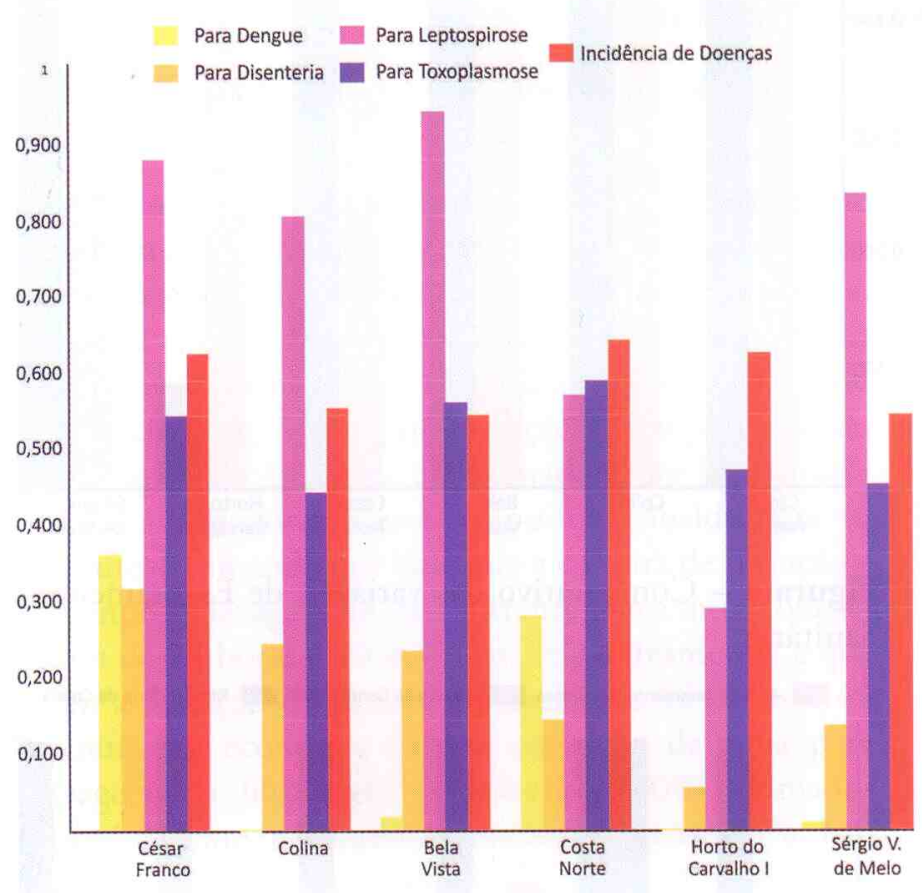

Figura 6 - Comparativo das variáveis de Controle de Vetores

Todos apresentaram pontuaçóes baixas para Dengue e para Disenteria, exceto César Franco. Para Leptospirose, todos apresentaram ótima pontuaçáo, exceto Costa Norte e Horto do Carvalho I. Para Toxoplasmose, todos se situaram na faixa intermediária, exceto Colina, com maior quantidade de vetores. Quanto à Incidência de Doenças, todos se situaram na faixa intermediária.

A Circulaçáo é satisfatória em todos os empreendimentos, destacando-se César Franco, Sérgio Vieira de Melo, Costa Norte e Colina. A Pavimentação também é satisfatória, e apenas a pontuaçáo do Colina ficou um pouco mais baixa (devido à inexistência de calçadas

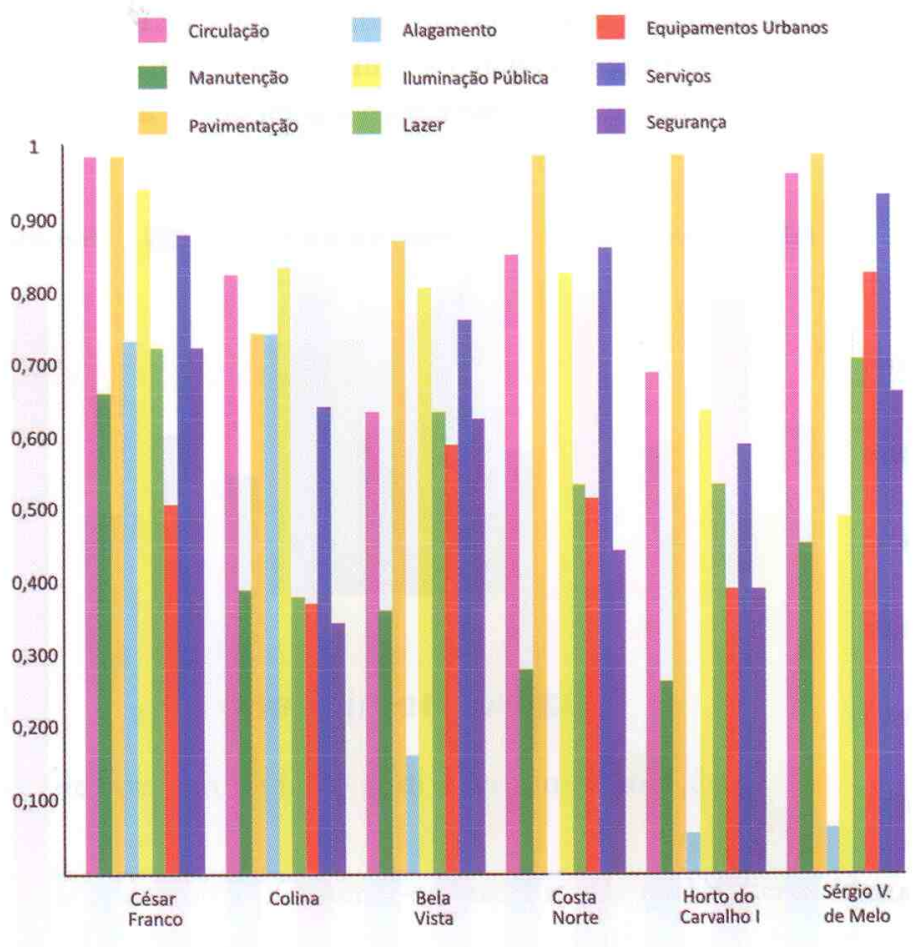

Figura 7 - Comparativo das variáveis de Espaço Público

cimentadas no entorno). A Iluminação Pública também é muito boa, exceto para Horto do Carvalho I e Sérgio Vieira de Melo, cujos moradores estáo insatisfeitos com sua baixa intensidade. Os Serviços são pontos fortes no César Franco, Costa Norte e Sérgio Vieira de Melo. Os demais situaram-se na faixa intermediária. Entretanto, a Manutençấo é ruim no Costa Norte e Horto do Carvalho I, com problemas também nos demais, exceto César Franco. Da mesma forma, os Alagamentos sáo frequentes, exceto César Franco e Colina. Quanto a Lazer, todos apresentaram pontuaçăo intermediária, exceto Colina (com pouquíssimas opçóes). Para Equipamentos Urbanos, houve destaque positivo para Sérgio Vieira de Melo e negativo para Colina e Horto do Carvalho I, situados em áreas mais isoladas e com menos infra-estrutura. Os demais situaram-se na faixa intermediária. Para Segurança, foram evidenciados problemas no Colina, Costa Norte e Horto do Carvalho $\mathrm{I}$, e os demais ficaram na faixa intermediária.

Para Materiais, o destaque positivo é César Franco e o negativo, Horto do Carvalho I (com grande incidência de umidade), sendo que os demais também apresentaram problemas. As Instalaçóes Elétricas e Hidro-Sanitárias também são problemáticas, com destaque para Horto do Carvalho I (em razão de problemas elétricos), ficando os demais com baixa pontuaçáo, exceto Colina (na faixa intermediária). Quanto a Conforto Ambiental, ninguém se destacou, exceto Horto do Carvalho I, 


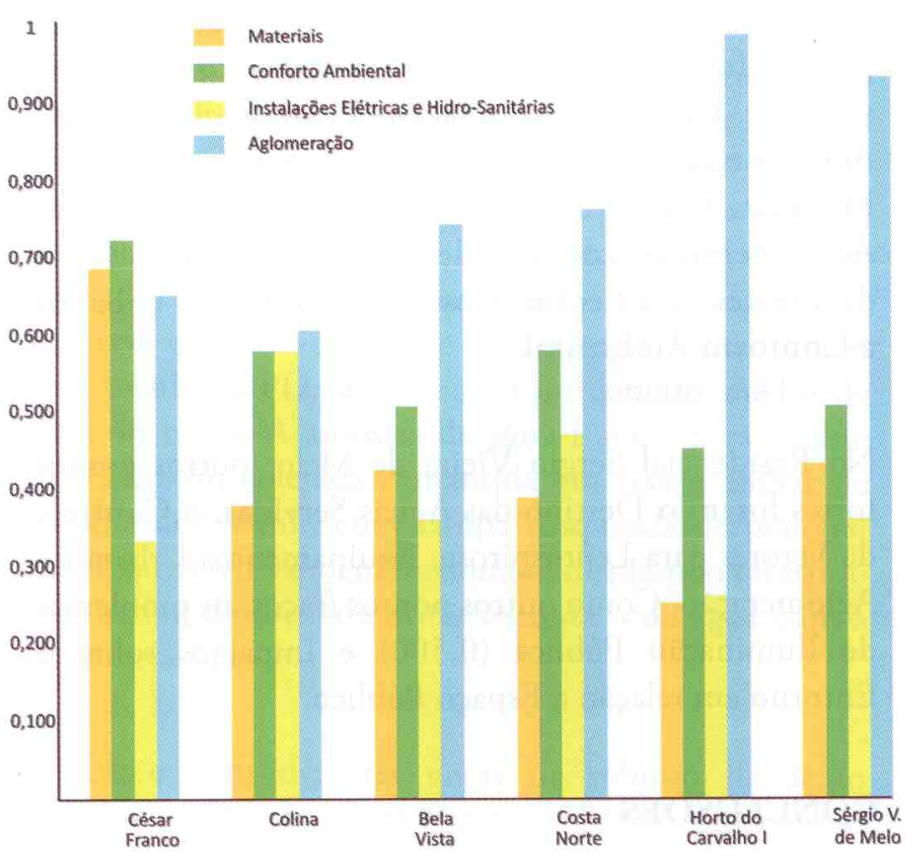

Figura 8 - Comparativo das variáveis de Condiçóes de Moradia

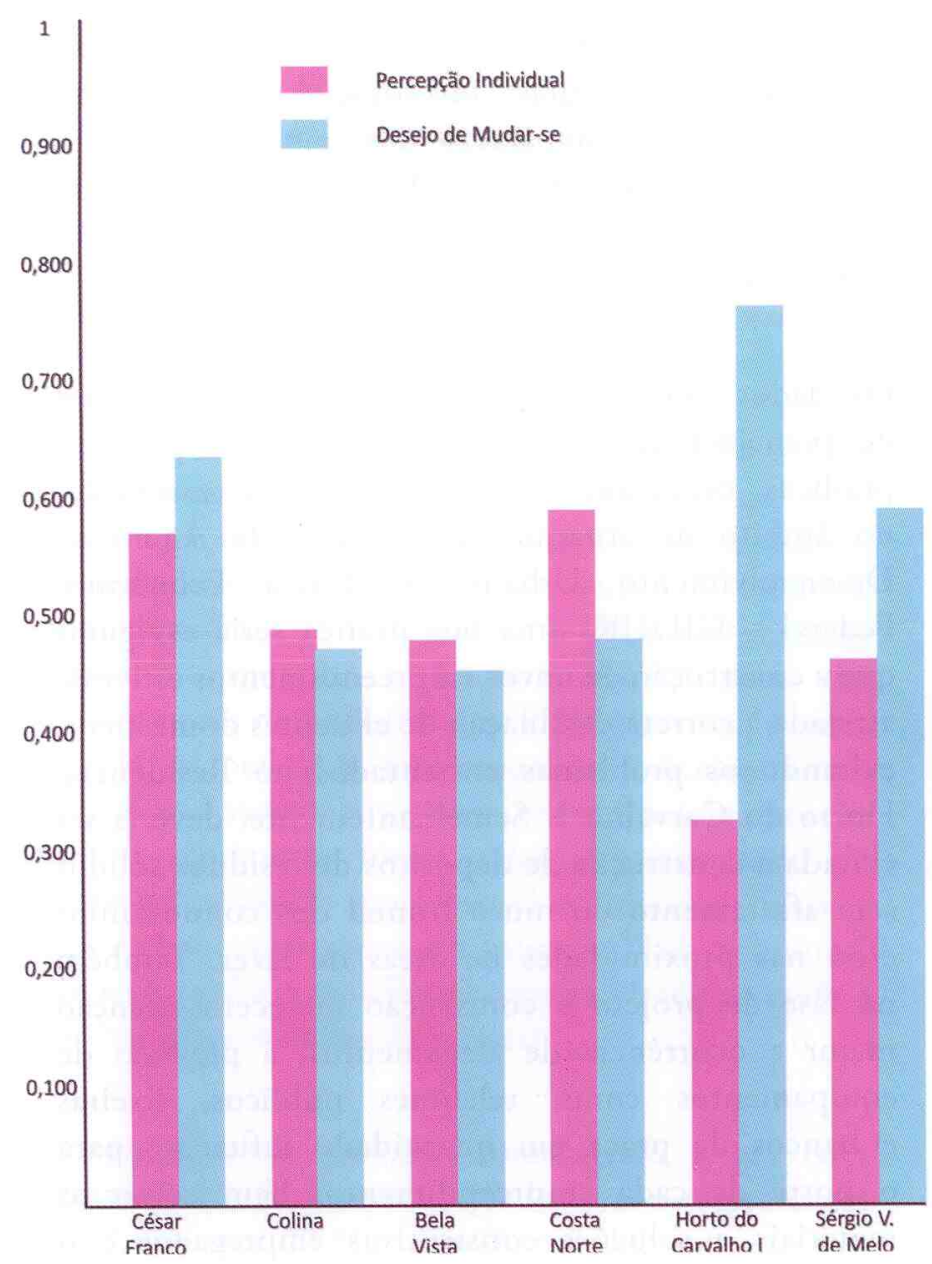

Figura 9 - Comparativo das variáveis de Satisfação com a Moradia com baixa pontuação devido a problemas de muita umidade, temperatura interna elevada no veráo e poluiçáo (especialmente odores provenientes da sarjeta). A Aglomeraçáo foi excelente para Horto do Carvalho I e Sérgio Vieira de Melo, os únicos empreendimentos pesquisados que dispóem de 3 quartos. Os demais situaram-se na faixa intermediária.

De acordo com a Percepção Individual, os empreendimentos que mais contribuíram para a melhoria da qualidade de vida de seus habitantes foram Costa Norte e César Franco, e o que menos contribuiu foi Horto do Carvalho I (instalado em área onde, inicialmente, não havia infra-estrutura de serviços urbanos). Os demais situaram-se na faixa intermediária. Todavia, Horto do Carvalho I também é o que apresenta moradores mais satisfeitos com sua moradia (devido à implantaçáo posterior de serviços urbanos e à valorização da área), enquanto Bela Vista, Colina e Costa Norte são os que possuem os moradores mais insatisfeitos, devido a problemas nas áreas de segurança, lazer e organização do condomínio. César Franco e Sérgio Vieira de Melo situaram-se na faixa intermediária quanto a .

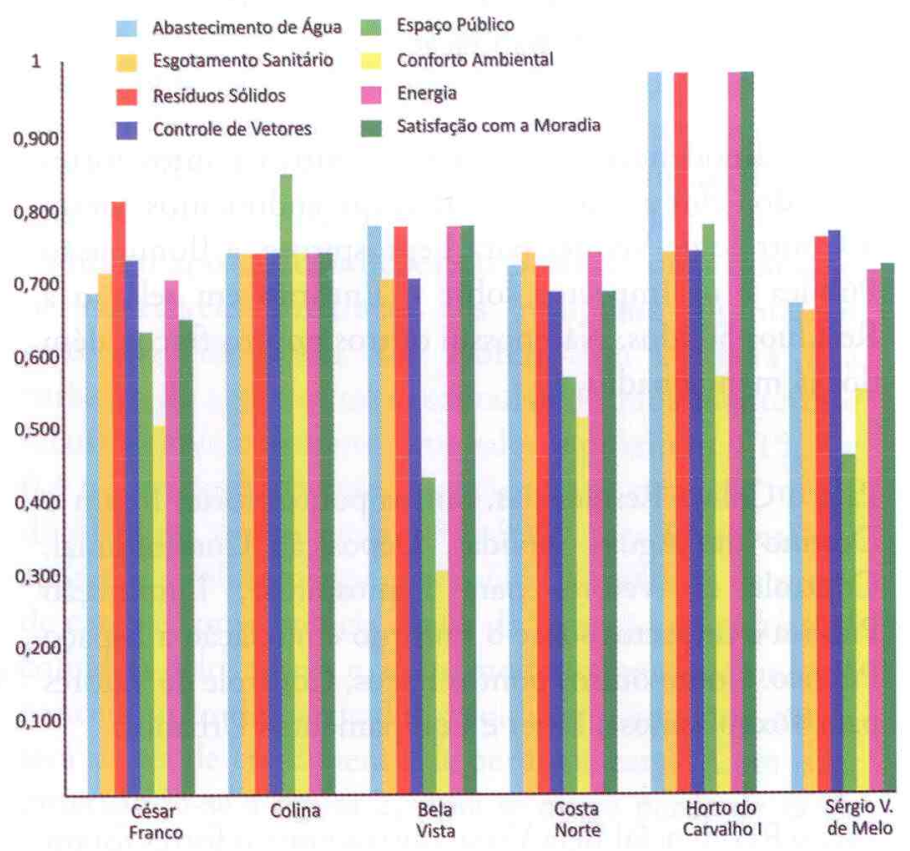

Figura 10 - Comparativo das variáveis de Impactos sobre o Entorno

O empreendimento com impactos mais positivos sobre o entorno foi Horto do Carvalho I, com pontuaçáo máxima em relação a Abastecimento de Água, Resíduos Sólidos, Energia (serviços que foram ampliados com a instalação praticamente pioneira do empreendimento na regiāo) e Satisfação com a Moradia. Também se 
destacam os impactos causados por César Franco em Resíduos Sólidos e Colina em Espaço Público. Por outro lado, Bela Vista trouxe poucos impactos positivos em relaçẫo a Espaço Público e Conforto Ambiental.

\section{DISCUSSÃO}

Os pontos fortes comuns a todos os empreendimentos foram a Reservaçáo e a Regularidade de Coleta. Merecem destaque positivo também as variáveis Qualidade da Água, Circulação, Pavimentaçăo e Serviços.

Os pontos fracos comuns foram o Controle de Vetores para Dengue e Disenteria. Merecem destaque negativo também as variáveis Frequência do Abastecimento, Deposiçáo Condominial, Manutençấo, Alagamento, Segurança, Materiais, Instalações Elétricas e HidroSanitárias, Percepção Individual e Desejo de Mudar-se. É possível relacionar as variáveis Percepção Individual e Desejo de Mudar-se com as demais variáveis mencionadas, pois as deficiências nelas verificadas influem efetivamente na satisfaçáo dos moradores e, consequentemente, em sua intençấo de procurar algo melhor em termos de habitaçấo.

Para o Residencial César Franco, outros pontos fortes além dos comuns a todos os empreendimentos foram o Controle de Vetores para Leptospirose, a Iluminação Pública e os Impactos sobre o Entorno em relação a Resíduos Sólidos. Não possui outros pontos fracos além dos já mencionados.

Para o Colina Residências, outros pontos fortes foram o Destino das Águas Servidas, Deposição Condominial, Controle de Vetores para Leptospirose, Iluminação Pública e Impactos sobre o Entorno em relação a Espaço Público. Como outros pontos fracos, Controle de Vetores para Toxoplasmose, Lazer e Equipamentos Urbanos.

Para o Residencial Bela Vista, outros pontos fortes foram o Destino das Águas Servidas, o Acondicionamento Doméstico, o Controle de Vetores para Leptospirose e a Iluminaçáo Pública. Como outros pontos fracos, os Impactos sobre o Entorno em relaçáo a Espaço Público e Conforto Ambiental.

Para o Residencial Costa Norte, outros pontos fortes foram o Destino das Águas Servidas, o Acondicionamento Doméstico e a Iluminação Pública. Náo houve pontos fracos adicionais.
Para o Residencial Horto do Carvalho I, outros pontos fortes foram a Aglomeração e os Impactos sobre o Entorno em relação a Abastecimento de Água, Resíduos Sólidos, Energia e Satisfação com a Moradia. Como outro ponto fraco, o Destino das Águas Servidas, com problemas também de Controle de Vetores para Leptospirose, Equipamentos Urbanos e Conforto Ambiental.

No Residencial Sérgio Vieira de Melo, outros pontos fortes foram o Destino das Águas Servidas, o Controle de Vetores para Leptospirose, Equipamentos Urbanos e Aglomeraçáo. Como outros pontos fracos, os problemas de Iluminação Pública $(0,500)$ e Impactos sobre o Entorno em relação a Espaço Público.

\section{CONCLUSÓES}

O modelo mostrou-se viável para o escopo urbano, podendo subsidiar novos estudos e pesquisas, especialmente os voltados à análise de empreendimentos habitacionais, podendo e devendo ser aperfeiçoado e voltar-se a futuras investigaçóes, englobando, por exemplo, a comparaçáo dos impactos sobre os beneficiários com aqueles sofridos pelos ocupantes do entorno e a comparaçáo entre empreendimentos habitacionais de cidades diversas.

Os dados obtidos podem ser utilizados em açóes de planejamento e acompanhamento de políticas públicas, otimizando investimentos. Neste sentido, no âmbito de atuaçáa da Gerência de Apoio ao Desenvolvimento Urbano da Caixa Econômica Federal - GIDUR, uma boa prática seria assegurar que a construçẫo de novos empreendimentos estivesse atrelada à correta destinação de efluentes domésticos, evitando os problemas enfrentados no Residencial Horto do Carvalho I. Semelhantemente, deveria ser evitada a construçáo de depósitos de resíduos sólidos sem afastamento do muro frontal dos condomínios e/ou nas proximidades de áreas de lazer. Também na fase de projeto e construçáo mereceria atençáa maior a ocorrência de alagamentos, a previsão de equipamentos como telefones públicos, lixeiras e bancos de praça em quantidade suficiente para o porte de cada empreendimento, bem como os materiais e soluçốes construtivas empregados e o dimensionamento de instalaçóes elétricas compatíveis com a norma e as necessidades usuais de famílias da classe a que se destinam. 
Quanto à Gerência de Alienação de Bens Móveis e Imóveis da Caixa Econômica Federal - GILIE, seria interessante uma açáo mais incisiva quanto à atuação das administradoras, especialmente no tocante à resoluçấo de problemas ligados à reservaçăo de água e deposiçấo condominial no Residencial Sérgio Vieira de Melo. Do mesmo modo, os problemas de manutençấo dos espaços públicos internos aos empreendimentos e de segurança também deveriam ser atacados.

\section{REFERÊNCIAS}

ALMEIDA, M. A. P. de; ABIKO, A. K. Indicadores de salubridade ambiental em favelas localizadas em áreas de proteçáo aos mananciais: o caso da favela Jardim Floresta. São Paulo: EPUSP, 2000. 28 p.

BATISTA, M. E. M.; SILVA, T. C. da. O modelo ISA/ JP - Indicador de performance para diagnóstico do saneamento ambiental urbano. Engenharia Sanitária e Ambiental, Rio de Janeiro, mar. 2006. Disponível em: $<$ http://www.scielo.br>. Acesso em: 07 jul. 2008.

BRASIL. Programa de Aceleraçáo do Crescimento 2007-2010. Brasília: 2007. Disponível em: <http:// www.fazenda.gov.br/portugues/releases/2007/r220107PAC-integra.pdf>. Acesso em: 01 nov. 2007.

CAIXA ECONÔMICA FEDERAL. Cartilha do PAR. S. 1.: 2008, 24 p. Disponível em: <http://downloads. caixa.gov.br/_arquivos/habita/par/CARTILHA_PAR_ V16.pdf>. Acesso em: 11 out. 2009.

CAMARGO, A. L. de B. Desenvolvimento sustentável: dimensôes e desafios. Campinas: Papirus, 2003. 160 p.
CARVALHO, B. de A. Ecologia aplicada ao saneamento ambiental. Rio de Janeiro: ABES, 1980. 368 p.

CORREAA, A. W. de M.; ANJOS, M. V. M. dos. História de Sergipe para vestibulares e outros concursos. Aracaju: Info Graphic's, 2007. 63 p.

DALTRO FILHO, J. Saneamento ambiental: doença, saúde e o saneamento da água. São Cristóvão: Editora da UFS; Aracaju: Fundação Oviêdo Teixeira, 2004. 331 p.

DIAS, M. C.; BORJA, P. C.; MORAES, L. R. S. Índice de Salubridade Ambiental em áreas de ocupaçáo espontâneas: um estudo em Salvador - Bahia. Engenharia Sanitária e Ambiental, Rio de Janeiro, jan./mar. 2004. Disponível em: <http://www.abes-dn. org.br>. Acesso em: 07 jul. 2008.

DIEGUES, A. C. S. O mito moderno da natureza intocada. São Paulo: Hucitec, 1996.

GOMES, G. M.; SOUZA, H. R. de; MAGALHĀES, A. R. (Orgs.). Desenvolvimento sustentável no Nordeste. Brasília: IPEA, 1995. 377 p.

LEFF, E. Saber ambiental: sustentabilidade, racionalidade, complexidade, poder. Petrópolis: Vozes, 2001. 494 p.

SILVA, N. V. S. da. As condiçóes de salubridade ambiental das comunidades periurbanas da bacia do baixo Gramame: diagnóstico e proposiçáo de benefícios. João Pessoa: Curso de Pós-Graduação em Engenharia Urbana, Universidade Federal da Paraíba (UFPB), 2006. 122 p. Dissertação de Mestrado. 